\title{
Analysis of the Influencing Factors of Residents' Travel Behavior Based on the Traffic Safety
}

\author{
LI Bing ${ }^{1, a}$, CAO Jin-xin ${ }^{1, b}$
}

Institute of Transportation, Inner Mongolia University, Hohhot, 010070, China

axsjlibing@163.com, ${ }^{b}$ imucjx@163.com

Keywords: Traffic safety; Travel behavior; Travel information; SP investigation; Exploratory Factor Analysis; Structural Equation Modeling;

Abstract: Residents' travel behavior are affected by many factors, traffic safety is an important considered factor. The decision of residents' travel is based on the safety consideration. In order to analysis the residents' travel behavior, it is necessary to comprehensively consider the travelers' physiological and psychological special selection in some certain circumstances, and to consider the travelers' economic basis and social conditions and the size of the urban construction traffic facilities, efficiency and operation mode, etc. This paper investigates the factors influencing the residents' travel behavior, using exploratory factor analysis method to draw the influence factors of residents' travel behavior, and then adopted confirmatory factor analysis to validate the result of exploratory factor analysis, and to explore the relationship between these impact factors.

\section{Introduction}

Residents choose a mode of transportation in the process of travel, will consider a variety of factors, and safety is well regulated factors, from the external environment to traffic conditions to the safety of transportation will affect the residents' travel behavior of a series of decision problem. So analyzing the influence factors of residents' travel behavior, comprehensively consider the traveler in certain circumstances special selection, individual characteristics, family structure, economic basis, social conditions, the transport efficiency and operation mode will affect the residents' travel choice.

In $1980 \mathrm{~s}$, researchers gradually pay attention to the traveler's own characteristic and influencing factors of travel behavior related analysis [1-4], researchers recognize that the traveler different individual characteristics, different surroundings, different people choose the results are also different. Composed of different ages in different travel purpose, different ways of travel distance of travel choice behavior is different.

At present most of the scholars are studying on how to use intelligent transportation information to guide residents travel behavior, the research content including: the practical and real-time performance of information research, traffic information on commuter travel, complex travel, as well as the tracking software research and development, etc. Through the RP and SP survey, some scholars study the effects of physiological and psychological behavior of the residents, economic and environmental factors, and then through the model to explore the potential driving force behind the travel choice.

\section{Methodologies}

Exploratory Factor Analysis. EFA is a statistical method used to identify the underlying relationships between observable variables. It attributes most of the variation to a few common factors through the covariance matrix, or correlative coefficient matrix, based on the relevance theory (Hair etal.,2010). The mathematical model is as follows:

$$
x_{i}=\lambda_{i 1} \xi_{1}+\lambda_{i 2} \xi_{2}+\mathrm{L}+\lambda_{i n} \xi_{n}+\delta_{i}, i=1,2, \mathrm{~L}, q, n \leq q
$$

Where $x_{1}, x_{2}, \mathrm{~L}, x_{q}$ are observable variables (or indicators), $\xi_{1}, \xi_{2} \mathrm{~L} \xi_{q}$ are common factors (or latent

variables), $\lambda_{i j}$ is estimated coefficient, called factor loading. Its statistical significance represents the 
correlation between the observed variables and common factors. Since the observed variables and common factors are standardized variables, the correlative coefficient matrix is equal to the covariance matrix, and ${ }^{\delta_{i}}$ is the error term.

This paper uses Principal Component Analysis method to obtain factor loading $\lambda_{i j}$.PCA is a statistical method that uses orthogonal transformation to convert a set of possibly correlated observed variables into linearly uncorrelated principal components, i.e. the common factors in EFA. The general form of PCA can be expressed as follows:

$$
\left\{\begin{array}{c}
y_{1}=r_{11} x_{1}+r_{12} x_{2}+\mathrm{L} r_{1 q} x_{q} \\
y_{2}=r_{21} x_{1}+r_{22} x_{2}+\mathrm{L} r_{2 q} x_{q} \\
\mathrm{LL} \\
y_{n}=r_{n 1} x_{1}+r_{n 2} x_{2}+\mathrm{L} r_{n q} x_{q}
\end{array}\right.
$$

Where ${ }^{r_{i j}}$ is the orthogonal eigenvector component of their corresponding eigenvalue for the covariance matrix of observed variables. The first principal component has the largest possible variance, and each succeeding component in turn has the highest variance possible under the constraint. Because the observed variables and the common factors are standardized variables, their variance is equal to one. This study utilizes the eigenvalue-greater-than-one rule to determine the number of principal components or common factors included in the model.

In general ,there are two basic principles to determine whether the variables are valid without cross loadings or not: The variable commonalities are considered "high" if their factor loadings are more than 0.5 , the variable should be dropped from the analysis if there are several high loadings $(0.5$ or better) on two or more factors. In addition, the Kaiser-Meyer-Olkin (KMO) and Bartlett testing are usually performed first to verify whether the correlation matrix is the identity matrix at the beginning of EFA. It is necessary to carry out the factor analysis if the KMO values are above 0.7and Bartlett testing statistical significance is less than 0.01 in the measurement table.

Structural Equation Modeling Analysis. SEM is a statistical technique for testing and estimating causal relations using a combination of statistical data and qualitative causal assumptions. It is based on the variables of covariance matrix to analyze the relationship between statistical methods, is actually a general linear model, including measurement model and structure model, and embodies the perfect combination of traditional path analysis and factor analysis. SEM generally use the Maximum Likelihood estimation model (Maximum-Likelihood, ML) structural equation analysis of path coefficient estimate, because the ML method enables researchers to modify the model based on the results of data analysis.

Usually a complete structural equation model contains two basic models: measurement model and structure model. Measurement model reflecting the relationship between the observed variables, the structure model reflects the relationship between the latent variables. The measurement model can be expressed by:

$$
\begin{aligned}
& y=\Lambda_{y} \eta+\varepsilon \\
& x=\Lambda_{x} \xi+\delta
\end{aligned}
$$

Where Eq. (3) is the measurement model for the endogenous variables, ${ }^{y}$ is a ${ }^{p \times 1}$ vector that contains ${ }^{p}$ endogenous indicators, and $\eta^{\text {is a }}{ }^{m \times 1}$ vector that contains $m$ endogenous latent variables, $\Lambda_{y}$ is a ${ }^{p \times m}$ factor loading matrix of ${ }^{y}$ in $^{\eta}$; Eq. (4) is the measurement model for the exogenous variables. $x$ is a $q \times 1$ vector that contains $q$ exogenous indicators, $\xi$ is a $n \times 1$ vector containing ${ }^{n}$ exogenous latent variables. $\Lambda_{x}$ is a ${ }^{q \times n}$ factor loading matrix of $x$ in $\xi, \varepsilon$ is a ${ }^{p \times 1}$ vector with ${ }^{p}$ errors, and $\delta$ is a ${ }^{q \times 1}$ vector with ${ }^{q}$ errors.

The structural equation is written as:

$\eta=B \eta+\Gamma \xi+\zeta$ 
Where $B$ is a $m \times m$ coefficient matrix, which describes the causal influences of endogenous latent variables upon one another. $\Gamma$ is a $m \times n$ coefficient matrix, which describes the causal influences between exogenous latent variables and endogenous latent variables; $\zeta$ is a ${ }^{m \times 1}$ residual error vector.

\section{Data and Survey}

Questionnaire Design. The questionnaire is divided into three parts: the first part is the demographic characteristics, including gender, age, education, occupation and income; The second part is the household characteristics: including family size, the number of children, the number of cars, whether to need to pick up the child and family nearby public transportation convenience. The third part is the travel behavior characteristics: travel costs, parking charge, physical output, stable travel mode, flexible travel mode and traffic information impact on pre-travel and en-route, etc. Send out 400 questionnaires, take back effective questionnaire 351, effective questionnaire recovery rate was $87.75 \%$.

Travel behavior is a complex choice process, it is often a traveler according to historical experience and improvised scene to make the complex decision, can also be defined travel behavior factors associated with decision-making, the decision-making behavior of different decision factors for support, but can be roughly outline based on the traffic investigation and analysis of different types of individual travel preferences and primary and secondary supporting factors. The analysis of influence factors can be roughly divided into the following categories:

(1) Personal characteristics: different individuals have travel information awareness and emergency response capacity, and decisions are often about the individual psychological feeling and physiological comfort, every time travel behavior is often the economic basis, social function, traffic environment and a combination of self-awareness, and so can extend through personal factors have a lot of related decision-making level.

(2) Family characteristics: based on the research of the domestic data often can induce the information of bus lines covering efficiency, allocation proportion of travel tools, special family consisting of travel demand (students need for pick-up or the elderly travel research), etc.

(3) Transport properties: different groups pay attention to different factors, the perception of traffic information and feedback ability difference, the adaptation and expect benefit of transportation infrastructure will also vary, such as the recognition degree of urban road network, whether by changing the path to avoid congestion at a critical point; the distribution proportion is reasonable, the public transportation whether there is a convenient transfer hub; traffic information release and guidance whether can be directly passed to the target population, etc.). 
Tab.1 The definition of variables

\begin{tabular}{|c|c|c|}
\hline Variable types & Variable name & Explanation \\
\hline \multirow{5}{*}{$\begin{array}{c}\text { Personal } \\
\text { characteristics }\end{array}$} & Gender & $1=$ male; 2 =female \\
\hline & Age & $1=$ under $18,2=18-30,3=31-55,4=$ above 55 \\
\hline & Occupation & $1=$ student, $2=$ manager, $3=$ staff, $4=$ freelance, $5=$ retired \\
\hline & Monthly income & $1=0, \quad 2=$ under $3000,3=3000-7000,4=$ above 7000 \\
\hline & Education & 1=under high school, 2=Bachelor, 3=above Master \\
\hline \multirow{5}{*}{$\begin{array}{c}\text { Household } \\
\text { characteristics }\end{array}$} & Family size & $\geq 0$ integers \\
\hline & Number of children & $\geq 0$ integers \\
\hline & Number of family cars & $\geq 0$ integers \\
\hline & Whether need to pick up children & $1=$ yes, $2=$ no \\
\hline & Bus convenience & $1=$ yes, $2=$ no \\
\hline \multirow{5}{*}{$\begin{array}{c}\text { Travel } \\
\text { characteristics }\end{array}$} & Stable travel mode & 1=Bicycle, $2=$ Metro, $3=$ Bus,4=Car,5=Walk \\
\hline & Flexible travel mode & $1=$ Bicycle, $2=$ Metro, $3=$ Bus, $4=$ Car, $5=$ Walk \\
\hline & Travel costs(RMB) & $1=0-20,2=21-40,3=$ above 41 \\
\hline & Parking charge(RMB) & $1=1-10,2=11-20,3=21-30,4=$ above 31 \\
\hline & Physical output & $1=\mathrm{a}$ few, $2=$ moderae, $3=$ great \\
\hline \multirow{4}{*}{$\begin{array}{l}\text { Information } \\
\text { influence } \\
\text { before travel }\end{array}$} & Information inquiry & $1=\mathrm{a}$ few, $2=$ moderae, $3=$ great \\
\hline & Trip mode changes & $1=$ no, $2=$ yes \\
\hline & Route changes & $1=$ no, $2=$ yes \\
\hline & Time changes & $1=$ no, $2=$ yes \\
\hline \multirow{3}{*}{$\begin{array}{l}\text { Information } \\
\text { influence on } \\
\text { road }\end{array}$} & Information inquiry & $1=\mathrm{a}$ few, $2=$ moderae, $3=$ great \\
\hline & Trip mode changes & $1=$ no, $2=$ yes \\
\hline & Route changes & $1=$ no, $2=$ yes \\
\hline
\end{tabular}

\section{Research Results}

Reliability and Validity Test. In order to guarantee the reliability of the questionnaire survey data, using SPSS software to carry out the reliability analysis on the observed variables. Results show that the Cronbach's Alpha coefficient is 0.634 , shows that scale has good internal consistency. Each basic dimension of model the Cronbach's Alpha coefficient are shown in table 2, all are greater than 0.5 , so the sample data is reliable. EFA and SEM should have non-overlapping samples, from the 500 valid questionnaires, 150 were selected for EFA and 350 for SEM.

Tab.2 Analysis results of questionnaire reliability

\begin{tabular}{c|c|c}
\hline Constructs & Variables & Cronbach's Alpha coefficient \\
\hline Personal characteristics & 5 & 0.649 \\
\hline Household characteristics & 5 & 0.657 \\
\hline Travel characteristics & 5 & 0.682 \\
\hline Information influence before travel & 4 & 0.779 \\
\hline Information influence on road & 3 & 0.755 \\
\hline
\end{tabular}

Exploratory factor analysis. The KMO and Bartlett testing results show that the KMO values are 0.712 and Bartlett testing values are 1245.808 and statistic Sig. are equal to 0.00 . Therefore, there is a significant correlation between the variables and it is necessary to carry out factor analysis. The results are shown in table 3. The factor loading of the common factors are all more than 0.60 , there is no serious cross-load. After orthogonal rotation, get five common factors, the cumulative variance contribution rate is $66.54 \%$. Therefore, the extracting factors can explain the information contained in the original variables. According to the specific attributes of the variables, the meaning of the extracting factors can be well explained. 
Tab.3 Exploratory factor analysis results

\begin{tabular}{|c|c|c|c|c|c|}
\hline \multirow{2}{*}{ Factors } & \multicolumn{5}{|c|}{ Common Factors } \\
\hline & 1 & 2 & 3 & 4 & 5 \\
\hline Route changes pre-travel & .873 & & & & \\
\hline Time changes pre-travel & .866 & & & & \\
\hline Information inquiry pre-travel & .746 & & & & \\
\hline Trip mode changes pre-travel & .684 & & & & \\
\hline Travel costs & & .834 & & & \\
\hline Stable travel mode & & .787 & & & \\
\hline Flexible travel mode & & .729 & & & \\
\hline Parking charge & & .631 & & & \\
\hline Age & & & .774 & & \\
\hline Occupation & & & .765 & & \\
\hline Monthly income & & & .755 & & \\
\hline Education & & & & & \\
\hline Number of children & & & & .870 & \\
\hline Family size & & & & .857 & \\
\hline Bus convenience & & & & .728 & \\
\hline Whether need to pick up children & & & & & \\
\hline Route changes on road & & & & & .834 \\
\hline Trip mode changes en-route & & & & & .738 \\
\hline Information inquiry en-route & & & & & .702 \\
\hline Physical output & & & & & \\
\hline Gender & & & & & \\
\hline Number of family cars & & & & & \\
\hline
\end{tabular}

Confirmatory factor analysis. Using AMOS22.0 to confirmatory factor analysis of measurement model, it is concluded that the standardization of observation variable load values, to remove less than 0.4 the observation variable, the other remaining variable values between 0.42 to 0.78 , qualify for greater than $0.4, \mathrm{t}$ test value are significant at the 0.01 level. Explain the observed variables can explain well the corresponding latent variables. By fitting inspection find some fitting index did not reach rational value, the concrete numerical value shown in table 4 . According to the principle of a release of a hypothesis model correction step by step, can find that CFI, IFI, NFI and NNFI reached more than 0.9 standard, RMSEA is 0.032 , it is less than 0.05 degree of model fit which is good, and AGFI near to 0.9 standard. In general the revised fit of the model is better. Figure1 is the parameters for structural equation path diagram.

Tab.4 Goodness-of-fit indices of residents' travel behavior

\begin{tabular}{|c|c|c|c|c|c|c|c|c|}
\hline \multirow{2}{*}{ Fitting index } & \multicolumn{3}{|c|}{ Absolute fitting index } & \multicolumn{5}{|c|}{ Value-added fitting index } \\
\hline & $\chi^{2} / d f$ & GFI & RMSEA & AGFI & NFI & CFI & IFI & NNFI \\
\hline Ideal value & $1-3$ & $>0.9$ & $<0.05$ & $>0.9$ & $>0.9$ & $>0.9$ & $>0.9$ & $>0.9$ \\
\hline Hypothesis model & 2.441 & 0.854 & 0.063 & 0.836 & 0.754 & 0.834 & 0.838 & 0.865 \\
\hline Modified model & 1.534 & 0.902 & 0.032 & 0.894 & 0.906 & 0.924 & 0.936 & 0.973 \\
\hline
\end{tabular}




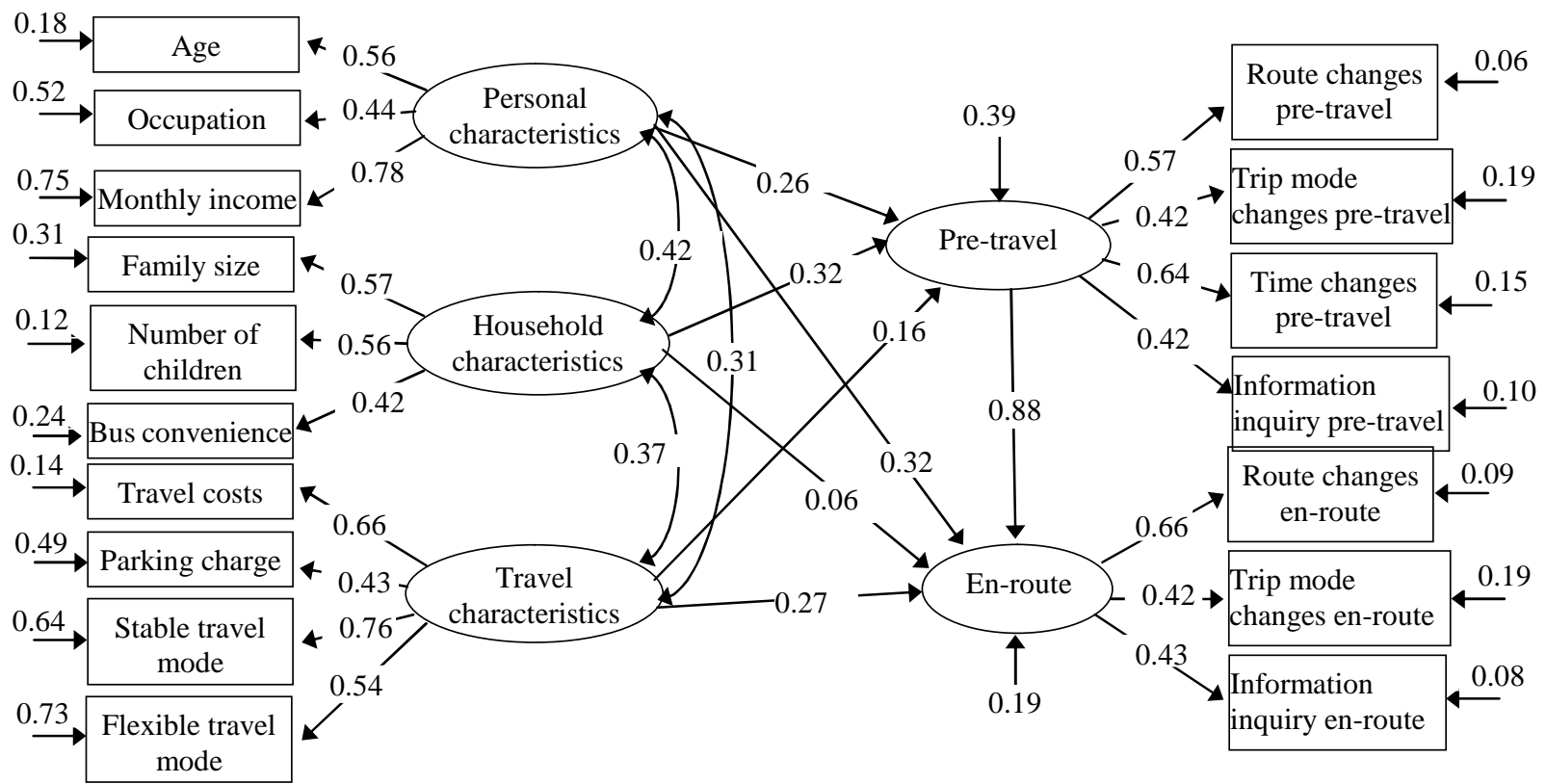

Fig.1 Final path diagram and relationship of structural model

\section{Conclusions}

Through the questionnaire, gain the influence factors of residents' travel behavior. The research divides into two stages: the first stage use exploratory factor analysis method, find out personal property, age, occupation, income, become the main influencing factors; Family property, family population, the number of children and family nearby public transportation convenience to become main factors that influence the effect of family travel; Travel attributes, such as travel costs, parking charge, stable travel mode and flexible travel mode will become the main factors influencing the residents' travel behavior; The second stage uses the structural equation model to confirmatory factor analysis of survey data, the same as the exploratory factor analysis results, and further concludes that the mutual relationship between impact factors. In the survey find that the travel behavior of people more and more influenced by traffic information, people can at any time according to traffic information to change the travel time, route and tools. Through the phone app for traffic information such as residents become the preferred way of access to information.

\section{Acknowledgements}

The work is supported by the Scientific Research Projects of Institution of Higher Education of Inner Mongolia Autonomous Region (Grant No.NJZY13006), the National Natural Science Foundation of China (Grant No. 71262008), the Scientific Research Foundation for the Returned Overseas Chinese Scholars, State Education Ministry, and Young Talent on Science and Technology Program of University in Inner Mongolia (Grant No. NJYT-13-B02).

\section{References}

[1] Zhang Feifei, Liu Beibei, Bi Jun, Chen Jin. Traffic Alternatives for Urban Residents and Affecting Factors[J].SiChuan Environment, 2012,31(3):132-138.

[2] Zhou Qian,Lu Huapu,Xu Wei.Comparison and Analysis of Urban Resident Trip Characteristics [J].Central South Highway Engineering, 2007,32(2):145-149. 
[3] Guo Hanying. Research on the traveler behavior based on the traveler physiology and psychology characteristics [D].South West JiaoTong University,2007.

[4] Xu Renting. Research on the travel destination and mode choice model based on individual traveler behavior characteristics [D].South East University,2007.

[5] Wang bobin, Shao chunfu, Li juan,Weng jinxian Ji xun. Holiday travel behavior analysis and empirical study under integrated multimodal travel information service[J],Transport policy,2015.

[6] Wang Xie, $\mathrm{Wu}$ Xiaogen,Zhang Jinhe,et al. Investigating influencing factors of tourism consumption coupon effect based on structural equation model approach: A case study of Hangzhou Geographical Research[J],2012,31(3): 543-554.

[7] Xinyu Cao· Patricia L. Mokhtarian ·Susan L. Handy. Do changes in neighborhood characteristics lead to changes in travel behavior? A structural equations modeling approach [J].Transportation,2007, 34:535-556.

[8] Arefeh Nasri, Lei Zhang. Assessing the Impact of Metropolitan-Level, County-Level,and Local-Level Built Environment on Travel Behavior:Evidence from 19 U.S. Urban Areas[J].Urban plan,2015,141.

[9] Jing Peng,Juan Zhicai,Gao Linjie. Application of the Expanded Theory of Planned Behavior in Intercity Travel Behavior[J]. Discrete Dynamics in Nature and Society,2014.

[10] Wu Minglong. Structural Equation Model: Operation and Application of AMOS. Chongqing: Chongqing University Press, 2009. 